\title{
The Use of E-learning in Foreign Language Learning: A Case Study of Undergraduate EFL Students
}

\author{
Laachir Abdelouahed \\ Faculty of letters and human sciences-Ibn Tofail University, Morocco \\ Abdolaachir97@gmail.com
}

DOI: https://doi.org/10.36892/ijlls.v1i3.79

$\begin{array}{ll}\begin{array}{l}\text { Received: } \\ \text { 13/10/2019 }\end{array} & \text { Abstract } \\ \text { This research paper is intended to shed light on the use of e-learning in } \\ \text { 1/12/2019 } & \text { learning and more particularly in foreign language learning by EFL students } \\ & \text { in higher education either to support the process of their traditional learning } \\ & \text { or for any other independent learning purposes. The aim is to identify how e- } \\ \text { Keywords: } & \text { learning is used, the various existing e-learning strategies that students prefer } \\ \text { E-Learning Tools; } & \text { to learn with and the extent to which EFL students are satisfied with the } \\ \text { Higher Education; } & \text { support offered by e-learning to assist the process of EFL learning. To answer } \\ \text { EFL Students; EFL } & \text { these queries, a quantitative method is adopted for the collection of data using } \\ \text { Learning } & \text { online tools in the creation and the administration of the questionnaire to the } \\ & \text { respondents. The findings of the study demonstrate that students usually use e- } \\ & \text { learning as it helps them to develop many language skills including } \\ & \text { communication skills, problem solving skills besides the four language skills. } \\ & \text { It has been shown also that students are highly satisfied with the use of e- } \\ & \text { learning which is usually used by traditional learning students to fulfill the } \\ & \text { missing gaps. }\end{array}$

1. INTRODUCTION

The world nowadays knows a historical technology revolution. There has been a quick development of technology and its use in the world and in Morocco in particular. In other words, technology has simply revolutionized our lives by covering our diverse and numerous needs and by providing human beings with the most useful and amazing resources as well as tools that can be used to achieve several goals by giving access to all sort of information in a very easy way. The terms E-learning and online learning are usually thought to hold the same meaning, thus, both terms are used to refer to distance learning through ICTs. However, the two terms are different and refer to two distinct and separate forms of learning. Bates (2005) explains this difference between e-learning and online and states that "the terms e-learning and online learning are often used interchangeably, although e-learning can encompass any form of telecommunications and computer-based learning, while online learning means using specifically the Internet and the Web" (p. 23). This research highlights the use of e-learning in foreign language learning in higher education in the Moroccan context. Thus, this study intends to investigate common techniques used in foreign language learning and the extent to which students do support these up-dated methods in addition to their impact on the language learning.

\subsection{Statement of the Problem}

Living in a globalized work characterized by an expansion of technology necessitates the use of technological tools. The $21^{\text {st }}$ century we are living in is mainly known for the large amount 
of information that exist in technology-based data; it mandatory to be equipped with these tools not only in daily life, but also in our learning. Having said that, the problematic issue of this paper is mainly to address the e-learning approach and how it can contribute to effective foreign language learning for undergraduate students of higher education in Morocco. The study will make a focus on the students' satisfaction with the use of e-learning for foreign language learning purposes as well. It also highlights the possible e-learning tool used by EFL learners in their studies.

\subsection{Research Questions}

The present study aims at answering the following questions:

1-To what extent are the students motivated to learn a foreign language using E-learning strategies?

2-What e-learning strategies are used by learners in the process of EFL learning?

3- How can e-learning contribute to effective foreign language learning?

4-To what degree are the students satisfied with use of e-learning in foreign language learning?

\subsection{Research objectives}

The specific objectives that this study tries to attain are the following:

To explore the e-learning tool used by Moroccan higher education students.

To investigate how e-learning can contribute to effective foreign language learning

To find out the extent to which students are satisfied with the use of e-learning in higher education.

\section{THEORETICAL BACKGROUND}

As people move into the twenty first century, the dependency on using computers and new information technologies in many aspects of life become more and more prevailing. As a result, technology has reorganized how we live, communicate and most importantly how we learn. If used suitably, technology can be a strong educational support in the process of learning and teaching as well. In the literature, the issue of e-learning which generally refers to the use of technological devises for learning purposes has been debated deeply by many researchers (Laachir, 2019; Sun, Tsai, Finger, Chen \& Yeh, 2007) as it represents one of the most controversial ways of learning and teaching through history. In education in general and in foreign language learning in particular, distance learning has become a crucial and a distinguished learning strategy which helps learners with constructing and building the required knowledge as they find themselves provided with many helping and facilitating features. For instance, virtual classes allow students to attend classes wherever they are without getting physically to the institute or the university they pursuit their studies in.

Before investigating the issue of e-learning and its use in foreign language learning as an effective up-dated strategy in higher education in the Moroccan context, an entrance to the previous studies and researches of this new way of knowledge construction will be introduced in the review of the literature in order to get familiar with the issue discussed in the present study. 


\subsection{E-Learning}

Sun et al. (2007) define e-learning as "a web-based system that makes information or knowledge available to users or learners and disregards time restrictions or geographic proximity" (p. 2). This statement shows one of the main characteristics that distinguish e-learning from traditional learning which is the separation of teacher and students during the process of learning and teaching. Thus, e-learning is considered as an independent and self-directed process of learning mainly supported by the adequate technological tools to make of it a workable learning and teaching method. Downes (2005) tackles the issue from a different angle and gives an explanation about e-learning by claiming that:

The e-learning application, therefore, begins to look very much like a blogging tool. It represents one node in a web of content, connected to other nodes and content creation services used by other students. It becomes, not an institutional or corporate application, but a personal learning center, where content is reused and remixed according to the student's own needs and interests. ( p.5)

The clarification given by Downes (2005) shows that e-learning can take the form of a personal learning center with specific content produced to fulfill students' own needs. He states also that the creation of content is not reserved to institutions only but students as well have this possibility to reuse contents and present them in a way to respond to students interests, which can make elearning look more like a blogging tool.

The use of enhanced technological support for learning purposes has increased in popularity as it plays more the role of a facilitator rather than a learning tool. Bates (2005) tackles the issue of e-learning and the growth of its use by claiming that "the main reason for the growth of third generation distance education is the rapid expansion of the Internet and in particular the World Wide Web. However, this is influencing not only distance but also conventional education" (p. 8). For him the principal reason behind the turn out on the use of distance education by learners is the noticeable expansion of Internet which has lead students with access to internet to use it not only as a medium of communication but also as a learning tool. Transforming the learning and development programs to the e-Learning domain is only possible with the presence of some specific means of technology; in that matter Bates (2005) has pointed out that "technology is a critical element of distance education" (p. 5). In his statement, Bates (2005) shows how distance education is mainly dependent on ICT which has come up with important and reliable strategies as well as a variety of educational techniques to promote learning and enhance knowledge.

Contrary to traditional learning, the direct or face-to-face interaction between instructor and student is absent in e-learning. Technology in that case plays the role of an intermediate between the student and his colleagues and instructors. It also provides the learner with all necessary material he may have recourse to during the process of learning. Keegan (2013) talked about this main characteristic of distance education. He said that:

Teaching at a distance is characterized by the separation of teacher and learner and of the learner from the learning group, with the interpersonal face to-face communication of conventional education being replaced by a personal mode of communication mediated by technology. (p.8)

\subsection{E-Learning and Online Learning}

The terms e-learning and online learning are usually thought to hold the same meaning and that both are used to refer to distance learning through ICTs. In fact, the two terms are different and refer to two distinct and separate forms of learning. Bates (2005) explains this difference 
between e-learning and online learning stating that "the terms e-learning and online learning are often used interchangeably, although e-learning can encompass any form of telecommunications and computer-based learning, while online learning means using specifically the Internet and the Web" (p. 8). In this illustration, Bates (2005) talks about the confusion that may occur between elearning and online learning by clarifying that e-learning, in fact, refers to the use of computer or other means of communication technologies used for learning purposes whereas online learning mainly designates the form of learning where Internet and the World Wide Web are used.

\subsection{Asynchronous and Synchronous E-learning:}

There was a debate in the literature about asynchronous and synchronous e-learning and how to distinguish between the two terms. Hrastinski (2008) points out that:

Asynchronous e- learning, is mainly facilitated by media such as email and discussion boards, supports work relations among learners and with teachers, even when participants cannot be online at the same time. It is thus a key component of flexible e-learning. In fact, many people take online courses because of their asynchronous nature, combining education with work, family, and other commitments. (p. 51)

In his clarification, Hrastinski (2008) explains that asynchronous e-learning is timeindependent and the learning can take place at any time which allows learners to make a balance between education and other life commitments without being pressed; self-paced course is one of the asynchronous e-learning examples. Hrastinski (2008) tackles the flexibility of asynchronous e-learning by claiming that "asynchronous e-learning makes it possible for learners to $\log$ on to an e-learning environment at any time and download documents or send messages to teachers or peers" (p. 52). Whereas synchronous e-learning events, which take place in real time, are based on communication between two people or more and thus, require them both to be present at a specific time. Video/audio conferencing are clear examples of synchronous e-learning activities. Hrastinski (2008) added that "Synchronous e-learning, commonly supported by media such as video conferencing and chat, has the potential to support e-learners in the development of learning communities" (p. 52). However, the choice of the adequate form of e-learning depends on the learner's own needs, interests, and time.

\subsection{E-learning Application to Foreign Language Learning}

\subsubsection{Advantages}

E-learning as a form of learning applied to foreign language learning counts many advantages which can be proven by the increase of its use among learners as a way to knowledge construction. Trajanovic, Domazet and Misic (2010) talk about one of the main advantages of elearning by stating that "the e-learning students, unlike classroom students, can also repeat the slides/narration as many times as they want, thus having more time for listening to the lectures/activities" (p. 446). They argue that contrary to traditional learning where students get the course merely once by attending class, e-learning students can repeat the course freely as many times as they desire until they understand the material which is very beneficial and crucial to effective foreign language learning.

It is impossible to talk about the advantages of e-learning without mentioning the flexibility of time and place; the learner is thus given the choice to study anywhere and anytime depending on his personal desire and commitments. In this regards, Bates (2005) states in his supportive views to e-learning that "students can study in their own time, at the place of their choice (home, 
work or learning Centre), and without face-to-face contact with a teacher"(p. 5). The face to face interaction between student and teacher is considered by some researchers as a disadvantage. In terms of English as a foreign language learning through e-learning, Trajanovic, Domazet and Misic (2010) added that "what is especially significant and needs special emphasis is the fact that there is a very strong support segment for the e-learning student from the teacher, who regularly communicates with them via e-mail, mostly in English, but if necessary also in their mother tongue" (p. 446). Communication between students and teachers through e-mails and other communication tools may in a way or in another compensate the absence of face-to-face interaction and give the student the chance to communicate with his instructor whenever he needs.

For Akturk and Gulsecen (2017), e-learning besides being low cost and affordable has a positive impact on language learning. They state that:

It has been seen that distance learning, which is quite advantageous in terms of students, academicians and administrations, has positive effects on language learning success. It was emphasized that giving part of the formal education courses by distance education would increase the quality of learning in universities. (p. 48)

They highlight the undeniable value and importance of distance learning programs in increasing the quality of language learning by providing the learners with the appropriate and updated courses and lessons of which they can make use during the learning process. Especially in terms of language learning, the e-learning programs where the learner can read and hear the lesson may be very beneficial and impactful. They allow the students to develop and enhance the four language skills starting with reading and listening when attending virtually the course and thus writing and speaking skills which will be unconsciously improved as a result. Listening to the course records is much more important than only reading the course in a form of a text. Though the importance of reading written versions of the lessons is undeniable in enhancing the writing and reading skills as well as the spelling of words, the combination of both records and text versions is still a more reliable learning method as listening is one of the crucial elements in language learning. Cai (2012) in studied e-learning and its role in developing the 4 languages skills and confirmed that "language acquisition should start from the auditory sense" (p. 3). He further added that "language ability is a kind of mental skill, which needs the right pedagogical strategies and training methods. E-learning will liberate the heavy labor of teachers', but also enable students to easily master English" (p. 6).

\subsubsection{Disadvantages:}

In terms of learning, more particularly in foreign language learning and despite the diversity of advantages that it offers to foreign language learners, e-learning counts some defects as well. Regardless of its vital role in language acquisition, some scholars have tackled the disadvantages of e-learning. For Solak and Cakir (2015), the absence of face-to-face interaction between the student and his instructor is one of the unpleasant characteristics of the foreign language learning through e-learning. They stated that "the application of distance learning system to foreign language teaching is a great challenge because the greatest problem is the lack of face-to-face communication among peers and their teachers" (p. 118). But still other scholars, including Laachir (2019) and Hamidi (2010), have their own perspective to contradict this claim by saying that the problem of the absence of direct interaction between students and instructors can be solved by the use of telecommunication tools which allow learners to keep in touch with their instructors such as e-mail and Skype. Mohammadi, Ghorbani and Hamidi (2011) have tackled the defects of e-learning used in foreign language learning from a social perspective by 
claiming that "e-learning decreases social relations among learners" (p. 465). Therefore, during the process of learning, each learner works separately with no real life interaction with other learners which affects the learner-learner relationship. Mohammadi, Ghorbani and Hamidi (2011) added that there are some people who are not capable of using technology effectively which hinders its importance in learning. It is of great importance to have certain knowledge in the correct use of the technological devices used during the process of e-learning; the lack of the adequate technical knowledge may affect negatively the equality and the kind of knowledge received.

\section{METHODOLOGY}

The previous section has undertaken the theoretical framework of the use of e-learning in learning and more particularly in foreign language learning, and which was mainly based on hypothetical issues rather than practical ones. This section will undertake the research methodology that will guide the whole practical part of this study as well as the presentation of the findings of the gathered data and the analysis of the obtained results.

\subsection{Research Design}

\subsubsection{Sample}

The choice of the sample is based on randomized sampling in which all participants have an equal opportunity to respond and to be subsequently selected. The sample of the present study contains 95 male and female respondents (65 respondents for S6, 21 respondents for S4 and 10 respondents for S2). They were selected from the undergraduate students of the English Department of Moulay Ismail University (Faculty of Letters and Humanities). The table below shows the distribution of respondents based on their university level:

\begin{tabular}{ll}
\multicolumn{2}{l}{ Table1. The Sample of the Study } \\
\hline University level & Number of students \\
\hline S2 & $\mathbf{1 0}$ \\
\hline S4 & $\mathbf{2 1}$ \\
\hline S6 & $\mathbf{6 5}$ \\
\hline Total & $\mathbf{9 5}$ \\
\hline
\end{tabular}

\subsubsection{Data Gathering Tool}

A questionnaire is used with the objective to collect quantitative data. It was created (using Google Forms) and administered to students of the English Department in their online learning groups by being posted in English department online groups and sent in private messages using social media to get as many responses as possible. The first section aims at collecting the demographic information where the respondent is required to determine first his gender by choosing one of the two options (Male of Female). The respondent should subsequently determine his university level by choosing one option among the three options: "S2" (First year), "S4" (second year) and "S6" (third year). The last option of the demographics is "Age" where the participant can choose one of the three available choices: "18-21", "22-24" and "25+".

Then the respondent moves to the next set of questions where he has to respond to other options related to the use of electronic tools as a medium to knowledge construction and foreign language learning (English as a foreign language). The choices differ from one question to another depending on its nature and requirements. Some of the questions are measured on the Likert- 
Scale in which there are either the four items: "always", "usually", "sometimes" and "never" or the items related to the respondent's agreement and which are: "strongly agree", "agree", "disagree", and "strongly disagree" whereas some other questions enable the participant to select more than one item such as the questions investigating the different language skills developed by the use e-learning during the process of foreign language learning. The questionnaire has been created, using Google Forms, and administered online in a randomized and equal way to the undergraduate students of the English department of Moulay Ismail University.

\section{RESULTS}

This section is devoted to present the findings of the gathered data as well as the analysis of the obtained results. It will also correlate the findings with the research questions of the study.

\section{Findings of the Demographics}

Table 2. Male and Female Participation in the Study

\begin{tabular}{lll}
\hline Gender & Frequency & Percentage \\
\hline Male & 47 & $49.5 \%$ \\
\hline Female & 48 & $50.5 \%$ \\
\hline NA & 0 & $0 \%$ \\
\hline Total & 95 & $100 \%$ \\
\hline
\end{tabular}

The Table 2 represents the participants based on their gender. Although the questionnaire was posted online to random students of the English department, the participation of Females and Males in the questionnaire is almost equal with a small difference of $0.5 \%$ in favor of females.

\section{Distribution of Age in MIU}

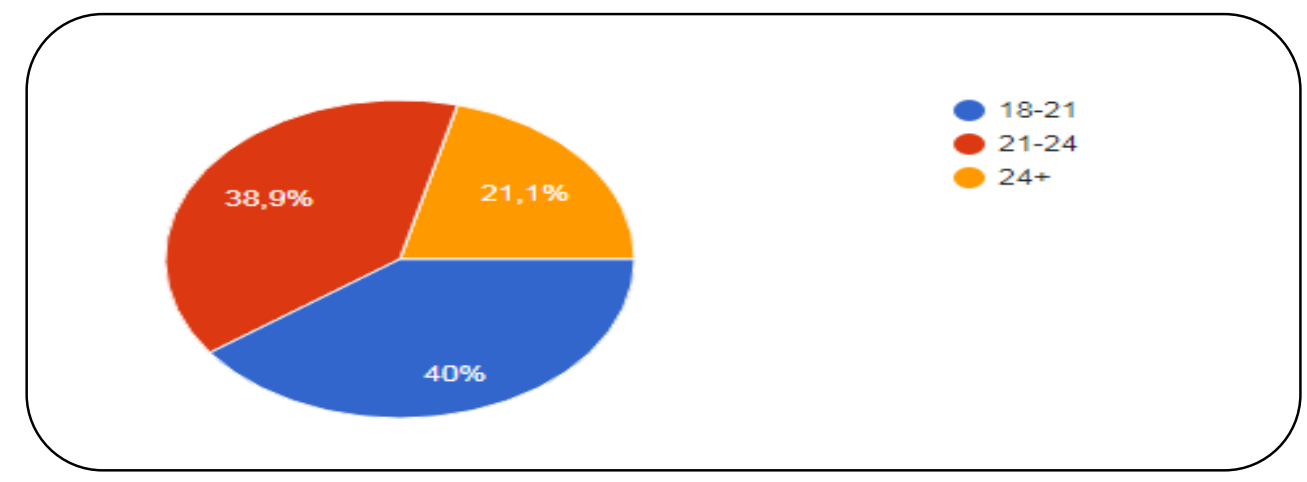

Figure 1. Percentage of the Participants' Age

Among demographic questions, the participants were asked about their age as well. The largest part of the population are aged between 18 and 21 with a total of 38 rating $400 \%$ of the whole population. Those who were at the ages ranging between 21 to 24 got the total number of 37 and scored the percentage of $38.9 \%$ whereas only 20 participants were ate ages elder than 24 with the percentage of $21.1 \%$.

\section{Distribution of the Use of Electronic Tools for Learning Purposes in MIU}


Table 3. E-learning Tools Usefulness

\begin{tabular}{lll}
\hline & Frequency & Percentage \\
\hline Always & 36 & $37.9 \%$ \\
\hline Usually & 41 & $43.2 \%$ \\
\hline Sometimes & 18 & $18.9 \%$ \\
\hline Never & 0 & $0 \%$ \\
\hline Total & 95 & $100 \%$ \\
\hline
\end{tabular}

In a total of 95 respondents, all the participants have claimed that they use electronic tools for learning purposes. The item "Usually" has taken the largest part with a total of 41 participants and at the percentage of $43.2 \%$ of the population followed by the item "Always" with a total of $37.9 \%$. The least scored item is "sometimes" with the percentage of $18.9 \%$ which indicates that tools are highly used by the learners to facilitate their learning process.

Table 4. Learning via E-tools is Conformable

\begin{tabular}{lll}
\hline & Frequency & Percentage \\
\hline Always & 29 & 30.5 \\
\hline Usually & 40 & 42.1 \\
\hline Sometimes & 25 & 26.3 \\
\hline Never & 1 & 1.1 \\
\hline Total & 95 & $100 \%$
\end{tabular}

The majority of students have claimed that they usually feel comfortable in learning via electronic tools with the percentage of $42.1 \%$. The total percentage of those who claimed that they always feel comfortable in using e-tools is $30.5 \%$ while $26.3 \%$ of them claimed that they sometimes feel comfortable. Amazingly, only one participant has chosen the item "Never" which indicates that the e-tools are considered as easy and comfortable means for learning.

Table 5. Online Learning is Enjoyable

\begin{tabular}{lll}
\hline & Frequency & Percentage \\
\hline Always & 26 & $27.4 \%$ \\
\hline Usually & 38 & $40.0 \%$ \\
\hline Sometimes & 24 & $25.3 \%$ \\
\hline Never & 7 & $7.4 \%$ \\
\hline Total & 95 & $100 \%$ \\
\hline
\end{tabular}

Table 5 shows the respondents' responses to the item "Do you enjoy being an online learner?". Participants had choices ranging from Always to Never depending on how often they enjoy being online learners. 26 of the respondents who ticked 'Always' constitute $27.4 \%$ of the population; 38 of them indicate that they usually enjoy learning online; 24 of the respondents' choice went to the option "Sometimes" whereas only 7 respondents have claimed that they never enjoy learning online with a total of $7.4 \%$. 
Table 6. Online Learning is Preferable to Traditional Learning

\begin{tabular}{lll}
\hline Items & Frequency & Percentage \\
\hline Yes & 48 & $50.53 \%$ \\
\hline No & 25 & $26.31 \%$ \\
\hline Both & 7 & $7.36 \%$ \\
\hline Sometimes/it depends & 5 & $5.26 \%$ \\
\hline NA & 10 & $10.52 \%$ \\
\hline Total & 95 & $100 \%$
\end{tabular}

As shown in the table 6 , a total of 48 respondents with the percentage of $50.53 \%$ have ticked "yes" before justifying their attitude (A summary of participants' justifications will be discussed in the next paragraph). 25 of the English Department students went for a "No" as they would prefer traditional learning strategies over e-learning. $7.36 \%$ of the population couldn't choose between the two and have explained that both approaches for them are crucial. 5 respondents representing $5.26 \%$ of the population said that sometimes they prefer e-learning to traditional ways of learning. On the other hand, 10 participants haven't responded to the question either because they did not see the question or they preferred to skip it out of laziness since it requires them to write justifications for their responses.

The justifications provided by the participants were surprising. A lot of them have explained their attitude and taken some of their time to give a clear and accurate opinion which seems to be very logical and to the point. Some of the participants have not given any justification and responded only with a YES or NO. The majority of those who responded with YES have noted that elearning overall saves time, money and energy, provides learners with lessons and courses in the easiest and most enjoyable way. Some of them mentioned other pluses that e-learning offers to its users such as the flexibility of time and place, the possibility to repeat the lesson several times until it is perfectly mastered, the availability of videos and images to help learners with their learning tasks, the freedom to control the process of learning as well as the use of adequate resources depending on the learner's own choice and needs. Other respondents justified their preference for e-learning by associating it with anxiety; they expressed how e-learning enables them to learn, do exercises and correct them online comfortably which is contrary to classroom learning where they may feel embarrassed by committing mistakes in the presence of other students, besides describing traditional learning by a boring.

For participants who responded with a "No" have noted that traditional learning allows them to interact with their colleagues and teachers, give their feedback. Thus it remains the basic way of knowledge construction. Some respondents associated their choice with health issues about how the use of computer-based learning can harm human body and cause many health problems. Respondents who have claimed that they prefer using both methods have said that effective learning needs the combination of different tools and approaches. Other respondents did not give a clear answer by claiming that the choice differs from one situation to another depending on the needs and the learning requirements. 
Table 7. E-learning is an Important Medium to Foreign Language Learning

\begin{tabular}{lll}
\hline & Frequency & Percentage \\
\hline Strongly Agree & 34 & $35.8 \%$ \\
\hline Agree & 57 & $60.0 \%$ \\
\hline Disagree & 2 & $2.1 \%$ \\
\hline Strongly disagree & 2 & $2.1 \%$ \\
\hline Total & 95 & $100 \%$
\end{tabular}

The Table 7 above reveals that the most frequently responses were represented in the items "Agree" and "Strongly Agree"; these two items scored the percentages of $60.0 \%$ and $35.8 \%$ respectfully. Whereas only 4 respondents disagreed with statement given. It indicates that elearning is greatly adapted by the learners due to its importance of improving the quality of foreign language learning.

Table 8. E-learning Methods Online EFL Learner Use

\begin{tabular}{lll}
\hline E-learning techniques used by EFL learner & Frequency & Percentage \\
\hline Social media & 53 & $55.8 \%$ \\
\hline Collaborative learning (blogs, chats, online discussions...) & 33 & $34.7 \%$ \\
\hline $\begin{array}{l}\text { E-learning communities or websites (Khan Academy, Coursera, } \\
\text { TedEd...) }\end{array}$ & 36 & $37.9 \%$ \\
\hline Video conferences/Virtual classes & 34 & $35.8 \%$ \\
\hline Simple E-learning ressources(E-lessons or online books...) & 52 & $54.7 \%$ \\
\hline Game-based learning & 15 & $15.8 \%$ \\
\hline
\end{tabular}

Among the questions that participants had to respond to was this one with multiple choices and which aims at investigating the e-learning techniques used by learners during the process of English as foreign language learning. Table 8 above shows that Social Media ranked the first with a total of 53 respondents, followed by simple e-learning resources such as e-books or elessons (e.g., pdf) with a total of 52 respondents representing $54.7 \%$ of the population. 33 respondents went for the use of blogs and chats and 36 for e-learning websites and communities whereas 34 respondents use video conferencing and virtual classes. Game-based learning is the least used e-learning technique by the participants.

Table 9. E-learning Contribution to Effective Foreign Language Learning

\begin{tabular}{lll}
\hline Statement & F $\%$ \\
\hline By using E-learning I could easily develop critical thinking skills. & 26 & 27.4 \\
\hline It enabled me to easily engage in knowledge and gain information in an enjoyable way. & 56 & 58.9 \\
\hline It enabled me to have access to information and knowledge whenever \& wherever I'm. & 56 & 58.9 \\
\hline E-learning has helped me to improve my problem solving skills. & 20 & 21.1 \\
\hline By E-learning I could expand my vocabulary and enhance my writing skills. & 50 & 52.6 \\
\hline My pronunciation has much improved in effortless ways. & 45 & 47.4 \\
\hline It enabled me to improve my communication skills. & 36 & 37.9 \\
\hline None of these. & 1 & 1.1 \\
\hline
\end{tabular}

To measure how foreign language learners could improve their language skills using e-learning, multiple items were raised. This section enables the participant to select as many items as he 
needs in order to describe the effect of e-learning on his foreign language knowledge. The first item was related to critical thinking skills where 26 out of respondents have noted that e-learning has enabled them to develop their critical thinking skills. The two items which have been selected the most (with 56 respondents for each) were the items that investigate whether e-learning allows the learners to be engaged easily in language knowledge and gain information in an enjoyable way and whether e-learning offers the possibility for the learners to learn anytime and anywhere as long as they hold the adequate technological material. The next item which is related to the role of e-learning in developing problem solving skills was selected by $21.1 \%$ of the population whereas $52.6 \%$ have agreed that e-learning has helped them expend their vocabulary and enhance their writing skills. 45 respondents out of 95 have admitted the positive impact of online learning on their pronunciation (e.g., via watching native speakers videos) representing $47.4 \%$ of the population. Improving communication skills was also an option which was selected by $37.9 \%$ of the respondents to confirm that their communication skills were enhanced by the use of elearning. The last option was "None of these" in case none of the existing items represent the effect of e-learning on the respondent's language learning; it was selected by only one respondent out of 95 .

Table 10. Students' Satisfaction with the Use of E-learning in Language Learning

\begin{tabular}{lll}
\hline Degree of satisfaction & Frequency & Percentage \\
\hline Very satisfied & 29 & $30.5 \%$ \\
\hline Satisfied & 62 & $65.3 \%$ \\
\hline Unsatisfied & 5 & $5.3 \%$ \\
\hline Total & 95 & $100 \%$
\end{tabular}

Table10 above represents the results of the question aiming at measuring the participants' satisfaction with the use of e-learning in foreign language learning. The statistical representation of data shows clearly that $65.3 \%$ of the participants are satisfied with the use of e-learning. $30.5 \%$ of the respondents have expressed the highest level of satisfaction whereas only 5 participants out of 95 have expressed their unsatisfaction of the use of e-learning in improving their second language learning level.

\section{DISCUSSION}

The previous section has dealt with the presentation of the data collected, while this section intends to shed light on the analyses and interpretation. It will also find the correlation between each research question raised at the beginning of the work to the findings with the results of this study.

It has been found that students of different gender, age and university level consider elearning as an important and enjoyable way of learning and prefer it over traditional learning. The majority of students have also claimed that for them e-learning is an important medium to foreign language learning. And according to their justifications, e-learning is useful and can be an effective learning tool; it allows its learner to be comfortable during the process of learning. The summary of the responses shows indirectly that by citing all these pluses, learners have shown how motivated they are to use e-learning in foreign language learning. It has been also noticed that learners use different strategies that vary from simple resources such as e-books or e-lessons to learning through social media, virtual classes or conferences, e-learning communities and websites as well as collaborative learning using forums, chats and online discussions. 
As to e-learning contribution to foreign language learning, students have selected many of the skills they could improve by the use of e-learning including critical thinking, problem solving, communication and writing skills besides enhancing learners' pronunciation by watching videos and hearing native speakers' pronunciation as well as expanding their vocabulary knowledge. Last but not least, it has been clear how satisfied students are. Besides the pluses they cited and the positive impression of students towards e-learning, a direct question was raised at the end of the questionnaire. It was used in the practical part to support the research and provide real data, and the results have shown that students are mostly satisfied with of e-learning in foreign language learning which responds perfectly to the question related to students' attitudes.

Using technology in education has become a necessity for students. E-learning revolutionized the way students learn and understand. It suggests new ways of learning in which the learner plays an active role and it emphasizes independent, flexible and collaborative learning. The learning process can be greatly enhanced through using electronic learning as it offers students many benefits and facilities that suit all types of learners. Unlike the traditional classrooms where students must attend their classes according to a specific schedule that might not suit them, virtual classrooms enable those learners to continue their study at their own pace and time. Additionally, instead of buying very expensive books, e-learning helps students have easy access to any kind of information they need using the internet as they can save costs and gain additional knowledge that the teacher may not provide them with in the classroom. Moreover, virtual classrooms help students gain a sense of collaboration and share knowledge and opinions with other students from their own country or from other different cultures.

Students rely on using different technological tools in their study that can support their learning inside the classroom and keep them motivated and have a strong will to study and be creative. As a result, many high educational institutions believe that this new way of learning and teaching can support the traditional way of learning in order to have a high education quality. Despite some challenges -as discussed in the literature review- the implementation of electronic learning system in universities is the first important step to an excellent future for education.

\section{CONCLUSION}

This research paper consists of 4 parts. The first is devoted to the introduction which gives a brief presentation about the topic investigated in this monograph research, comprises the variables, the statement problem and the research questions that this study is expected to answer. The second part is the review of the literature which shed light on what has been said by scholars and researches about the issues discussed in this study which are related to e-learning, its use by foreign language learners and other related issues. Part 3 has dealt with the methodology used to achieve the objectives of this study as well as the statistical representation of data gathered using the questionnaire instrument which was created online using Google Forms platform (Charts were also generated by Google Forms). Then it has reported the analyses and interpretation of data as well as the association of the obtained results and the research questions. The fourth part is this present part which generally concludes this present research project and highlights some of the limitations of this present study.

Nowadays, using technology in education has become a necessity for students. E-learning revolutionized the way students learn and understand. It suggests new ways of learning in which the learner plays an active role and it emphasizes independent, flexible and collaborative learning. The learning process can be greatly enhanced through using electronic learning as it offers students many benefits and facilities that suit all types of learners. Unlike the traditional 
classrooms where students must attend their classes according to a specific schedule that might not suit them, virtual classrooms enable those learners to continue their study at their own pace and time. Additionally, instead of buying very expensive books, e-learning helps students have easy access to any kind of information they need using the internet as a result they can save costs and gain additional knowledge that the teacher may not provide them with in the classroom. Moreover, virtual classrooms help students gain a sense of collaboration and share knowledge and opinions with other students from their own country or from other different cultures.

Student rely on different technological tools in their study that can support their learning inside the classroom and keep them motivated and have a strong will to study and be creative. As a result many high educational institutions believe that this new way of learning and teaching can support the traditional way of learning in order to have a high education quality. Despite some challenges -as discussed in the literature review- the implementation of electronic learning system in universities is the first important step to a better future.

\section{REFERENCES}

Bates, A. T. (2005). Technology, e-learning and distance education. (2nd edition.). Routledge. Retrieved from: https://www.amazon.com/Technology-learning-Distance-EducationRoutledge/dp/0415284376.

Cai, H. (2012). E-learning and English Teaching. IERI Procedia, 2,841-846.

Clark, R. C., \& Mayer, R. E. (2016). E-learning and the science of instruction: Proven guidelines for consumers and designers of multimedia learning. John Wiley \& Sons.

Downes, S. (2005). E-learning 2.0. Elearn magazine, 2005(10), 1. Retrieved from: https://elearnmag.acm.org/featured.cfm?aid=1104968

Hrastinski, S. (2008). Asynchronous and synchronous e-learning. Educause quarterly, 31(4), 51-55.

Keegan, D. (2013). Foundations of distance education.Routledge.

Laachir, A. (2019). The Implementation of Collaborative Learning via Virtual Communities in Moroccan Higher Education. International Journal of Language and Literary Studies, 1(2), 60-73. https://doi.org/10.36892/ijlls.v1i2.28

Navimipour, N. J., \& Zareie, B. (2015). A model for assessing the impact of e-learning systems on employees' satisfaction. Computers in Human Behavior, 53, 475-485.

Mohammadi, N., Ghorbani, V., \& Hamidi, F. (2011). Effects of e-learning on language learning. Procedia Computer Science, 3, 464-468.

Solak, E., \& Cakir, R. (2015). Language learning strategies of language e-learners in Turkey. ELearning and Digital Media, 12(1), 107-120.

Sun, P. C., Tsai, R. J., Finger, G., Chen, Y. Y., \&Yeh, D. (2008). What drives a successful eLearning? An empirical investigation of the critical factors influencing learner satisfaction. Computers \& Education, 50(4), 1183-1202.

Trajanovic, M., Domazet, D., \& Misic-Ilic, B. (2007). Distance learning and foreign language teaching. In Balkan Conference in Informatics (BCI 2007) (pp. 441-452).

Yi-Cheng, C., Chun-Yu, C., Yi-Chen, L., \& Ron-Chen, Y. (2007). Predicting College Student'Use of E-Learning Systems: An attempt to extend technology acceptance model. PACIS 2007 Proceedings, 121. 